\title{
Psychological adjustment and behaviours in children of migrant workers in China
}

Wang Feng, Institute of Social Medicine, Zhejiang University School of

Public Health

Zhou Xudong, Institute of Social Medicine, Zhejiang University School of

Public Health

Therese Hesketh, UCL Institute for Global Health, Institute of Global Health

Zhejiang University School of Medicine 


\section{Abstract}

Background In China there are around 274 million rural-urban migrants, an estimated 61 million children left behind in rural areas by parents, and 29 million children who accompany their parents to cities. The aim of this study was to compare the psychosocial adjustment and behaviours of leftbehind children and migrant children.

Methods Full data were available for 761 left-behind children and 1392 migrant children aged 11 to 17 in Zhejiang Province, eastern China. Participants completed a questionnaire focusing on migration status, risks behaviours, and psychological well-being measured with the Strengths and Difficulties Questionnaire.

Results There were more left behind girls and more urban migrant boys $(\mathrm{p}<0.001)$. The mean scores on the Strengths and Difficulties Questionnaire were all higher in left-behind children than migrant children: for emotional symptoms (3.82 vs $3.03, \mathrm{p}<0.001)$, conduct problems $(2.55$ vs 2.41 , $\mathrm{p}=0.048)$, hyperactivity $(4.25$ vs $3.81, \mathrm{p}<0.001)$ and total difficulties $(13.46$ vs $12.00, \mathrm{p}=0.020)$, while the prosocial score was lower ( 6.68 vs $6.90, \mathrm{p}<0.001)$, all indicating lower levels of wellbeing in left-behind children. Overall $11.4 \%$ of left-behind children and $8.8 \%$ of migrant children scored in the abnormal range for total difficulties. Left behind girls were particularly vulnerable to emotional problems. Left-behind children were more likely to admit to stealing and cheating on exams, but there were no differences in other risks behaviours, such as smoking and drinking.

Conclusions Migration with parents, rather than separation from parents, was associated with better psychological well-being and fewer behavioral problems. Our findings have relevance for migrant parents in helping to inform decisions about where to raise their children as well as for policy makers in countries where migration is a major issue. When children are left behind, models of community 
support need to be considered, especially for those who are most vulnerable. 


\section{Introduction}

Rural-to-urban migration for improved job opportunities and higher income is a massive global phenomenon. Many rural-urban migrants are parents who are faced with the choice of bringing their children with them to the urban destination, or leaving them behind in rural areas, often in the care of relatives. Their numbers globally are 763 million and separation from parents for reasons of work is a normal childhood experience in many countries (United Nations 2013).

China is currently witnessing what has been described as the largest migration in human history (Zhang 2004). An estimated 274 million or 35\% of the working population are classified as ruralurban migrants (National Bureau of Statistics of China 2014). Choices for migrant parents in relation to their children are difficult in China, because of the way in which the Chinese government controls rural-urban migration, mainly through the hukou household registration system. This system prevents rural hukou holders from taking-up permanent residence in cities, making them temporary residents, irrespective of their length of stay. Although this system is being gradually relaxed, a number of restrictions persist, especially in the bigger cities (Wu 2013). Importantly, migrants and their children are allowed only limited access to education, health, and other public services in destination cities (Peng 2011). These restrictions, together with the often precarious nature of migrant life, poor living conditions and long hours of work discourage most migrants from taking their children with them (Chen et al. 2009).

Currently in China there are an estimated 61 million left-behind children accounting for $38 \%$ of all rural children and 22\% of all children (All-China Women's Federation 2013). Of these nearly half or 29 million are living with neither parent, with over 2 million living alone. The number of left-behind children has increased only gradually over the last decade, increasing by $4 \%$ between 2005 and 2010 
(Duan 2015). In contrast numbers of children accompanying their parents, urban migrant children, have increased by $40 \%$ to an estimated 29 million (All-China Women's Federation 2013).

There is a growing literature about the effects of being left behind. Compared with children living with parents, left-behind children in China have been shown to be susceptible to psychological problems, including depression, anxiety, and loneliness (Chen et al. 2009; He et al. 2012; Jia et al. 2010; Jia \& Tian 2010; Cheng \& Sun 2015; Su et al. 2013), to have lower development outcomes (Wen \& Lin 2012), and to be more prone to behavioral problems, especially in adolescence (Chen et al. 2009).

Less attention has been paid to migrant children (Duan \& Yang 2008). Because of their hukou status, nearly all attend schools designated for migrant children (Wang 2008). They are thus marginalized in urban society, face challenges of social integration and acculturation, and are reported to be susceptible to mental health problems, such as depression and anxiety (Wong et al. 2009). In addition, living conditions for migrants are often not salubrious, and long working hours limit the time that migrants parents can spend with their children. Despite the obvious need for information for parents about the relative benefits and outcomes of leaving children behind or taking them with them to urban areas, there have been no studies which directly compare left-behind children with migrant children of the same age (Wu et al. 2015). Such information is crucial for parents themselves and policy-makers. The aim of this study therefore was to explore the effects of parental migration on the psychological well-being and behaviours of children through a comparison of leftbehind children and migrant children.

\section{Methods}

The study was a cross-sectional survey using self-completion questionnaires. It was part of a large 
multidisciplinary study, started in 2014, exploring the impact of parental migration on children's health and well-being. This part of the study was conducted in Zhejiang, a relatively wealthy southeastern coastal province, which is both a feeder and receiver location for migrant workers, with around 18 million migrant workers, 1.2 million left-behind children and nearly 2.8 million migrant children (Duan et al. 2013; Duan et al. 2013). The urban location for the study was Ningbo, the province's second largest city; the rural location was a poor county in Quzhou prefecture in western Zhejiang, where $50 \%$ of children are classified as left-behind (by at least one parent) and $25 \%$ by both parents.

\section{Sample}

In this study, left-behind children are defined as "children under 18 who have been left behind at their original residence while both parents migrate for work, and have been not living with them for at least six months". Migrant children are defined as "children under 18 who have left their original residence and migrated to a city with parents at least six months ago". Thirty schools, fifteen in urban Ningbo (schools for migrant children) and fifteen in rural Quzhou, were randomly selected from the list of registered schools at the Provincial Education Bureau. In each school, all the children from grade 5 to 8 , that is mostly aged 11 to 16 , were invited to participate. Younger children were not included, mainly because of the need to ensure the level of literacy necessary to complete the questionnaire. Researchers administered the questionnaire in the classroom without teachers present and assisted whenever necessary. Permission to conduct the study in the schools was obtained from the individual head teachers. Informed consent was obtained from children and their parents or guardian (through a letter sent home). They were told they could refuse to fill out any items and could stop at any point. Anonymity and confidentiality were assured. Given the sensitivity of some 
of the questions, participants were given the number of a psychological counselling service helpline, which would provide advice free-of-charge. To our knowledge, none of the children availed themselves of this offer. This study was approved by the research ethics committees of University College London and Zhejiang University.

\section{Measures}

Sociodemographic characteristics included gender, age, grade, and migration status. To determine a basic measure of economic status we asked children how they felt their household wealth compared with others in the community.

The Strength and Difficulties Questionnaire

Psychological adjustment and behaviours were assessed with the Chinese student version of the Strength and Difficulties Questionnaire, which has been validated for use in Chinese population (Goodman 1999; Goodman 1997; Kou et al. 2007). The student version, (as opposed to the parent or teacher versions) are regarded as most suitable in this age group. The Strength and Difficulties Questionnaire consists of 25 items, and is scored on a three-point Likert scale $(0=$ not true, $1=$ somewhat true, $2=$ certainly true). It has five subscales each with 5 -items: emotional symptoms, conduct problems, hyperactivity, peer problems, and pro-social behaviours. Each subscale score is calculated by summing the five items, and a total difficulties score is generated by summing the scores of all but the prosocial scale (thus ranging from 0 to 40) (Goodman 1999). In all subscales but the prosocial, higher scores indicate a tendency towards problematic behaviours and low sense of well-being. Scores can be analysed as a total and by individual subgroup, as continuous or categorical variables, the latter divisible into "normal", "borderline", or "abnormal" categories, corresponding to scores of 0-15, 16-19 and 20 and over. The cut-offs of "abnormal" of the five 
subgroups are as followed: emotional symptoms $(\geq 7)$, conduct problems $(\geq 5)$, hyperactivity $(\geq 7)$, peer problems $(\geq 6)$, prosocial $(\leqslant 4)$. (Goodman 1997; Kou et al. 2007)

\section{Risk behaviours}

Specific questions on risk behaviours were developed for this study, based partly on findings of previous work (Hesketh et al. 2010; Hesketh et al. 2011). These included questions on smoking, drinking, cheating on exams. The latter is a behavior of particular interest in the Chinese setting. Items were rated on a 3-point scale: never, sometimes and often. The questionnaire was piloted in one urban and one rural school, and amended according to feedback.

\section{Statistical analysis}

Descriptive analyses of the main variables were conducted, followed by bivariate analyses of key variables by child category and gender. The Strength and Difficulties Questionnaire was analysed as both continuous and categorical variables. For those emotional and behavioral indicators which were significant in the univariate analysis we controlled for gender, grade and self-rated socioeconomic status using logistic regression to compute adjusted odds ratios and 95\% confidence intervals. The data were analysed with SPSS 20.0 for Windows.

\section{Results}

Completed questionnaires were obtained from a total of 761 left-behind children and 1392 migrant children. This difference reflected the class sizes in the two settings. Of the total classroom sample $56(2.6 \%)$ refused to complete the questionnaire, $22(2.9 \%)$ of the left-behind children and $34(2.4 \%)$ of the migrant children, and a further $3 \%$ had to be discarded because of non-completion of key variables including parents migration and SDQ questions. Table 1 shows sociodemographic characteristics between left behind and migrant group. The age range was 11-17 years. Left-behind 
children were more likely to be girls and younger. In terms of self-reported comparative socioeconomic status there was no significant difference between left-behind children and migrant children.

Table 2 presents the frequency of "somewhat" and "certainly true" answers from each of the 25 items of the Strength and Difficulties Questionnaire for left behind and migrant children. Most notably left-behind children scored significantly higher on all emotional items, on anger and "fighting a lot" and on four out of five of the hyperactivity items. Key findings from the mean Strength and Difficulties Questionnaire scores for all five categories with comparisons shown by child group and gender are in Table 3. The total difficulties score and three difficulties subcategories were significantly higher in left-behind children. The score for the prosocial element was significantly lower in left-behind children. Except for emotional categories, boys scored higher on all the difficulties subscales and lower on the prosocial score. When analysed as categorical variables, a significantly high proportion of the children left behind (11.4\%) had an abnormal total difficulties score than did migrant children (8.8\%). (Table 5) The frequencies for the individual behaviour problems by gender and child group are listed in Table 4 . There are few differences in risk behaviours between left-behind and migrant groups. Nearly 9\% of left-behind children and $8 \%$ of migrant children ever smoked or smoked more than one cigarette per week. Over a quarter (26\%) of left-behind children and $25 \%$ of migrant children had ever drunk alcohol or drunk more than once per month. In general, left-behind children were more likely to engage in risk behaviors such as cheating on exams, stealing, and they were more likely to be bullied by others. Overall, boys had a higher prevalence of all risk behaviours.

Table 5 shows the association between migration status and emotional and behavioural indicators 
as categorical variables, that is levels of "abnormality" as defined by the Strength and Difficulties Questionnaire. Both left-behind children and migrant children show high levels of abnormality on the total difficulties score $11.4 \%$ and $8.8 \%$ respectively. After adjusting for gender, grade and selfrated socio-economic status, left-behind children are significantly more likely to score in the abnormal range for emotional difficulties, total difficulties and prosocial behaviour. They are also more likely to cheat on exams and to have experienced bullying.

\section{Discussion}

To our knowledge, this is the first study to directly compare the prevalence of emotional and risk behavioural problems between left-behind children and migrant children. We show that left-behind children are significantly more likely to report higher levels of emotional symptoms, higher total difficulties, and lower levels of prosocial behaviour than migrant children. In addition, we observed a higher prevalence of cheating, stealing and experience of bullying amongst left-behind children compared to their migrant counterparts. Our findings suggest that migration with parents, rather than separation from parents, is associated with more favorable emotional and behavioral adjustment.

Since the Strength and Difficulties Questionnaire has been widely used elsewhere, our results provide for illuminating comparisons with other populations. Comparison with the Strength and Difficulties Questionnaire scores in Europe, the United States, and African countries we showed that the left-behind children in our research score higher in terms of emotional symptoms, conduct problems, hyperactivity, peer problems and total difficulties, than in any other country (Essau et al. 2012; Obel et al. 2004; Marzocchi et al. 2004; Shojaei et al. 2009; Woerner et al. 2004; Kashala et al. 2005), as well as in the few Chinese studies where the Strength and Difficulties Questionnaire 
has been used (Kou et al. 2007; Fan et al. 2010; Hu et al. 2014). The Strength and Difficulties Questionnaire has been used as a screening tool for psychiatric disorders in children with those scoring as "abnormal" recommended for psychological assessment. So the finding that $11.4 \%$ of left-behind children and $8.8 \%$ of migrant children fall into the "abnormal" category should be of concern, in a setting where such psychological difficulties are not identified. Such children are at risk of psychological problems into adolescence and adulthood (Sourander et al. 2007; Caspi et al. 1996). This is clearly of concern given the very large numbers of left behind children across China. The finding that left-behind children are significantly more likely to cheat on exams, steal and suffer bullying may be partly a result of lack parents' supervision and care (Gao et al. 2010). But compared with many other countries, the relatively low proportions of children who have ever smoked or drunk alcohol may relate to the more traditional views of childhood in China. Previous research from China has shown that such risk behaviours tend to start after children leave school in both urban and rural areas (Hesketh et al. 2001).

Our findings show important gender differences. First, girls are more likely to be left behind and more boys accompany their parents, probably a manifestation of persisting son preference in much of rural China (Hesketh \& Zhu 1997). Second, girls consistently score higher on emotional symptoms but lower on conduct, hyperactivity and peer problem scores. Awareness of feeling less "preferred" and then being left behind may be particularly damaging to emotional well-being, especially during the years around puberty. From previous studies we believe that the return of a parent, especially a mother, is highly desirable during the early adolescent period (Wen \& Lin 2012). Given our findings, the trend toward whole family migration, thus a relative increase in migrant children and decrease in left-behind children, is encouraging (Duan 2015). China is currently 
undergoing a major hukou reform aimed at universal access to education, health, and other public services by year 2020, though this is unlikely to occur by then in the bigger cities, where migrant numbers are high. However, any relaxation in the hukou regulations will help to support whole family migration. However, at 61 million children, the total number of left-behind children is still over double that of migrant children. The Chinese government has expressed concerns about the well-being, development and future human capital of left-behind children and there have been a number of policy announcements about the need to address the problems of left-behind children over the past five years (All-China Women's Federation 2013). Most recently in February 2016, the government called for the establishment of a system that engages families, governments, schools and social groups in providing better care and protection to left-behind children (Government of China 2016), although details about how this should be done were notably absent. However, a number of models of community-based interventions are emerging, including our own intervention, conducted in collaboration with the Chinese Women's Federation, and comprising a network of "clubs" providing activities, support and a place of safety for left-behind children, with a focus on the most vulnerable.

This study has a number of limitations. First, such a cross-sectional study cannot establish cause and effect relationships. Longitudinal studies, which we are currently undertaking, will help to elucidate the long term effects of parental migration. Second, Zhejiang is a relatively wealthy province and with improved transport infrastructure, regular home visits are possible. This is in sharp contrast with migrants from poor western provinces who return home once per year at most, so psychological well-being in such children is likely to be worse. So this study may represent a best case scenario for left-behind children. Third, our study considered only a limited range of 
potential determinants: we did not explore areas such as age at first separation from parents, and the forms of caregiving the left-behind children receive during separation.

In conclusion, very high levels of rural-urban migration will continue in China for the foreseeable future. Our findings contribute to the debate about whether parents should take their children with them to cities or leave them behind in the care of relatives. When children are left behind, models of community support need to be considered, especially for the most vulnerable children.

Acknowledgements The authors thank all the schools and children for their participation.

Funding UBS Optimus Foundation.

\section{Competing interests None}

\section{Key messages:}

1、 No research has systematically compared psychological and behavioural problems in left behind and migrant children.

2、 Left behind children report significantly higher levels of emotional symptoms, and higher total psychological difficulties and more behavioural problems, than migrant children.

3、 Girls are more likely to be left behind and are especially vulnerable to emotional difficulties.

4、 Migration with parents, rather than separation from parents, is associated with more favorable emotional and behavioural adjustment.

\section{References:}

All-China Women's Federation (2013) National survey report on the situation of left-behind children and migrant children in China. Available at: http://www.women.org.cn/ (last accessed 25 November 2016). Caspi, A., Moffitt, T. E., Newman, D. L. \& Silva, P. A. (1996) Behavioral observations at age 3 years predict adult psychiatric disorders. Longitudinal evidence from a birth cohort. Archives of General Psychiatry, 53, 1033-1039. 
Chen, X., Wang, L. \& Wang, Z. (2009) Shyness-sensitivity and social, school, and psychological adjustment in rural migrant and urban children in China. Child Development, 80, 1499-1513.

Cheng, J. \& Sun, Y. H. (2015) Depression and anxiety among left-behind children in China: a systematic review. Child Care Health and Development, 41, 515-523.

Duan, C. (2015) Several key issues related with migrant children and left-behind children. China Agricultural University Journal of Social Science Edition, 32, 46-50.

Duan, C. \& Yang, K. (2008) The left-behind children in rural China. Population Research, 15-25.

Duan, C., Lv, L., Guo, J. \& Wang, Z. (2013) Survial and development of left-behind children in rural China: based on the analysis of sixth census data. Population Journal, 37-49.

Duan, C., Lv, L., Wang, Z. \& Guo, J. (2013) The survival and development status of floating children in China: an analysis of the sixth population census data. South China Population, 44-55.

Essau, C. A., Olaya, B., Anastassiou-Hadjicharalambous, X., Pauli, G., Gilvarry, C., Bray, D., O'Callaghan, J. \& Ollendick, T. H. (2012) Psychometric properties of the Strength and Difficulties Questionnaire from five European countries. International Journal of Methods in Psychiatric Research, 21, 232-245.

Fan, F., Su, L., Gill, M. K. \& Birmaher, B. (2010) Emotional and behavioral problems of Chinese leftbehind children: a preliminary study. Social Psychiatry and Psychiatric Epidemiology, 45, 655-664.

Gao, Y., Li, L. P., Kim, J. H., Congdon, N., Lau, J. \& Griffiths, S. (2010) The impact of parental migration on health status and health behaviours among left behind adolescent school children in China.

BioMed Central Public Health, 10, 56.

Goodman, R. (1997) The Strengths and Difficulties Questionnaire: a research note. Journal of Child Psychology and Psychiatry, 38, 581-586.

Goodman, R. (1999) The extended version of the Strengths and Difficulties Questionnaire as a guide to child psychiatric caseness and consequent burden. Journal of Child Psychology and Psychiatry, 40, 791799.

Government of China (2016) Strengthening the care and protection for rural left-behind children. Available at: http://www.gov.cn (last accessed 25 November 2016).

He, B., Fan, J., Liu, N., Li, H., Wang, Y., Williams, J. \& Wong, K. (2012) Depression risk of 'left-behind children' in rural China. Psychiatry Research, 200, 306-312.

Hesketh, T. \& Zhu, W. X. (1997) Health in China - The one child family policy: The good, the bad, and the ugly. British Medical Journal, 314, 1685-1687.

Hesketh, T., Ding, Q. J. \& Tomkins, A. (2001) Smoking among youths in China. American Journal of Public Health, 91, 1653-1655.

Hesketh, T., Yan, Z., Li, L., Zhou, X., Ye, X. \& Zhu, W. (2010) Stress and psychosomatic symptoms in Chinese school children: cross-sectional survey. Archives of Disease in Child, 95, 136-140.

Hesketh, T., Yan, Z., Ye, X., Zhu, W., Zhou, X. \& Li, L. (2011) Behaviour problems in Chinese primary school children. Social Psychiatry and Psychiatric Epidemiology, 46, 733-741.

Hu, H., Lu, S. \& Huang, C. (2014) The psychological and behavioral outcomes of migrant and leftbehind children in China. Children and Youth Services Review, 46, 1-10.

Jia, Z. \& Tian, W. (2010) Loneliness of left-behind children: a cross-sectional survey in a sample of rural China. Child Care Health and Development, 36, 812-817.

Jia, Z., Shi, L., Cao, Y., Delancey, J. \& Tian, W. (2010) Health-related quality of life of "left-behind children": a cross-sectional survey in rural China. Quality of Life Research, 19, 775-780.

Kashala, E., Elgen, I., Sommerfelt, K. \& Tylleskar, T. (2005) Teacher ratings of mental health among 
school children in Kinshasa, Democratic Republic of Congo. European Child and Adolescent Psychiatry, 14, 208-215.

Kou, J., Du, Y. \& Xia, L. (2007) Formulation of children Strength and Difficulties Questionnaire (the edition for students) for Shanghai norm. China Journal of Health Psychology, 3-5.

Marzocchi, G. M., Capron, C., Di Pietro, M., Duran, T. E., Duyme, M., Frigerio, A., Gaspar, M. F., Hamilton, H., Pithon, G., Simoes, A. \& Therond, C. (2004) The use of the Strengths and Difficulties Questionnaire (SDQ) in Southern European countries. European Child and Adolescent Psychiatry, 13 Suppl 2, I40-I46.

National Bureau of Statistics of China (2014) Statistical Communiqué of the People's Republic of China on the 2014 National Economic and Social Development. Available at: http://www.stats.gov.cn (last accessed 25 November 2016).

Obel, C., Heiervang, E., Rodriguez, A., Heyerdahl, S., Smedje, H., Sourander, A., Guethmundsson, O. O., Clench-Aas, J., Christensen, E., Heian, F., Mathiesen, K. S., Magnusson, P., Njarethvik, U., Koskelainen, M., Ronning, J. A., Stormark, K. M. \& Olsen, J. (2004) The Strengths and Difficulties Questionnaire in the Nordic countries. European Child and Adolescent Psychiatry, 13 Suppl 2, I32-I39. Peng, X. (2011) China's demographic history and future challenges. Science, 333, 581-587.

Shojaei, T., Wazana, A., Pitrou, I. \& Kovess, V. (2009) The Strengths and Difficulties Questionnaire: validation study in French school-aged children and cross-cultural comparisons. Social Psychiatry and Psychiatric Epidemiology, 44, 740-747.

Sourander, A., Jensen, P., Ronning, J. A., Niemela, S., Helenius, H., Sillanmaki, L., Kumpulainen, K., Piha, J., Tamminen, T., Moilanen, I. \& Almqvist, F. (2007) What is the early adulthood outcome of boys who bully or are bullied in childhood? The Finnish "from a boy to a man" study. Pediatrics, 120, 397404.

Su, S., Li, X., Lin, D., Xu, X. \& Zhu, M. (2013) Psychological adjustment among left-behind children in rural China: the role of parental migration and parent-child communication. Child Care Health and Development, 39, 162-170.

United Nations (2013) Cross-national comparisons of internal migration: An update on global patterns and trends. Available at: http://www.un.org/en/index.html (last accessed 25 November 2016).

Wang, L. (2008) The marginality of migrant children in the urban Chinese educational system. British Journal of Sociology of Education, 29, 691-703.

Wen, M. \& Lin, D. (2012) Child development in rural China: children left behind by their migrant parents and children of nonmigrant families. Child Development, 83, 120-136.

Woerner, W., Fleitlich-Bilyk, B., Martinussen, R., Fletcher, J., Cucchiaro, G., Dalgalarrondo, P., Lui, M. \& Tannock, R. (2004) The Strengths and Difficulties Questionnaire overseas: evaluations and applications of the SDQ beyond Europe. European Child and Adolescent Psychiatry, 13 Suppl 2, I47I54.

Wong, F. K. D., Chang, Y. L. \& He, X. S. (2009) Correlates of psychological wellbeing of children of migrant workers in Shanghai, China. Social Psychiatry and Psychiatric Epidemiology, 44, 815-824.

Wu, L. (2013) Decentralization and hukou reforms in China. Policy and Society, 32, 33-42.

Wu, Q., Lu, D. \& Kang, M. (2015) Social capital and the mental health of children in rural China with different experiences of parental migration. Social Science and Medicine, 132, 270-277.

Zhang, Q. F. (2004) Economic transition and new patterns of parent-adult child coresidence in urban china. Journal of Marriage and the Family, 66, 1231-1245. 
Table 1 The social-demographic characteristics of left-behind children (LBC) and migrant children (MC), $\mathrm{n}(\%)$

\begin{tabular}{lcccc}
\hline & LBC & MC & t or $\chi^{2}$ & $p$-value \\
& $\mathrm{N}=761$ & $\mathrm{~N}=1392$ & & \\
\hline Gender & & & 19.95 & $<0.001$ \\
$\quad$ Boy & $353(46.4)$ & $787(56.5)$ & & \\
$\quad$ Girl & $408(53.6)$ & $605(43.5)$ & & \\
Age, Mean(SD) & $13.0(1.2)$ & $13.4(1.3)$ & 7.43 & $<0.001$ \\
Grade & & & 29.61 & $<0.001$ \\
$\quad$ Grade5、Grade6 & $283(37.2)$ & $689(49.5)$ & & \\
$\quad$ Grade7、Grade8 & $478(62.8)$ & $703(50.5)$ & & \\
\hline
\end{tabular}




\begin{tabular}{lrrrr}
\hline Income level & & & 5.59 & 0.232 \\
Much better off & $12(1.6)$ & $19(1.4)$ & & \\
Better off & $120(15.8)$ & $212(15.2)$ & & \\
The same & $556(73.1)$ & $1002(72.0)$ & & \\
Poorer & $60(7.9)$ & $111(8.0)$ & & \\
Much poorer & $13(1.7)$ & $48(3.4)$ & & \\
\hline
\end{tabular}

Table 2 Comparison of Strength and Difficulties Questionnaire (SDQ) item between left-behind children (LBC) and migrant children (MC): figures show responses for somewhat true and certainly true, $n(\%)$

\begin{tabular}{|c|c|c|c|c|}
\hline & LBC & $\mathrm{MC}$ & \multirow{2}{*}{$\chi^{2}$} & \multirow{2}{*}{$p$-value } \\
\hline & $\mathrm{N}=761$ & $\mathrm{~N}=1392$ & & \\
\hline \multicolumn{5}{|l|}{ Emotional Symptoms Scale } \\
\hline I get a lot of headaches, stomach-aches or sickness. & $314(41.3)$ & $426(30.7)$ & 23.63 & $<0.001$ \\
\hline I worry a lot. & $686(90.3)$ & $1118(80.5)$ & 33.75 & $<0.001$ \\
\hline I am often unhappy, downhearted or tearful. & $377(49.6)$ & $530(38.3)$ & 25.39 & $<0.001$ \\
\hline I am nervous in new situations. & $525(69.1)$ & $806(58.0)$ & 25.17 & $<0.001$ \\
\hline I have many fears, I am easily scared. & $395(52.0)$ & $514(37.2)$ & 43.43 & $<0.001$ \\
\hline \multicolumn{5}{|l|}{ Conduct Problems Scale } \\
\hline I get very angry and often lose my temper & $529(69.6)$ & $862(62.1)$ & 11.64 & 0.001 \\
\hline I usually do as I am told. & $709(93.2)$ & $1276(92.1)$ & 0.71 & 0.401 \\
\hline I fight a lot. & $328(43.2)$ & $495(35.8)$ & 11.10 & 0.001 \\
\hline I am often accused of lying or cheating. & $175(23.0)$ & $357(25.7)$ & 1.80 & 0.180 \\
\hline I take things that are not mine. & $100(13.2)$ & $175(12.7)$ & 0.07 & 0.795 \\
\hline \multicolumn{5}{|l|}{ Hyperactivity Scale } \\
\hline I am restless. I cannot stay still for long. & $538(70.7)$ & $805(58.0)$ & 33.50 & $<0.001$ \\
\hline I am constantly fidgeting or squirming. & $480(63.3)$ & $678(49.0)$ & 39.75 & $<0.001$ \\
\hline I am easily distracted. & $563(74.1)$ & $882(63.7)$ & 23.45 & $<0.001$ \\
\hline I think before I do things. & $675(88.8)$ & $1185(85.6)$ & 4.24 & 0.040 \\
\hline I finish the work I am doing. & $655(86.2)$ & $1202(86.8)$ & 0.13 & 0.714 \\
\hline \multicolumn{5}{|l|}{ Peer Problems Scale } \\
\hline I am usually on my own. & $360(47.3)$ & $554(39.9)$ & 10.87 & 0.001 \\
\hline I have one good friend or more. & $712(93.7)$ & $1295(93.2)$ & 0.10 & 0.755 \\
\hline Other people my age generally like me. & 702(92.7) & $1255(90.5)$ & 2.68 & 0.101 \\
\hline Other children or young people pick on me. & $276(36.6)$ & $429(31.0)$ & 6.58 & 0.010 \\
\hline I get on better with adults than with people my age. & $489(64.3)$ & $982(71.1)$ & 10.13 & 0.001 \\
\hline \multicolumn{5}{|l|}{ Prosocial Scale } \\
\hline I try to be nice to other people. & $737(97.0)$ & $1347(97.1)$ & 0.00 & 0.958 \\
\hline I usually share with others. & $707(93.3)$ & $1286(92.9)$ & 0.08 & 0.783 \\
\hline I am helpful if someone is hurt, upset of feeling ill & $728(95.8)$ & 1312(94.5) & 1.55 & 0.214 \\
\hline I am kind to younger children. & $713(93.8)$ & 1345(97.0) & 11.53 & 0.001 \\
\hline I often volunteer to help others. & $695(91.6)$ & $1268(91.5)$ & 0.00 & 1.000 \\
\hline
\end{tabular}

Table 3 The Strength and Difficulties Questionnaire scoring by child group and gender, Mean (SD) 


\begin{tabular}{|c|c|c|c|c|c|c|c|c|c|c|}
\hline & $\begin{array}{l}\text { LBC, } \\
\text { male } \\
(n=353)\end{array}$ & $\begin{array}{l}\text { LBC, } \\
\text { female } \\
(n=408)\end{array}$ & $\begin{array}{l}\text { MC, } \\
\text { male } \\
(n=787)\end{array}$ & $\begin{array}{l}M C, \\
\text { female } \\
(n=605)\end{array}$ & $\begin{array}{l}\text { Total, } \\
\text { LBC } \\
(n=761)\end{array}$ & $\begin{array}{l}\text { Total, } \\
\text { MC } \\
(n=1392)\end{array}$ & $\begin{array}{l}p \text {-value } \\
\text { (lbc vs. } \\
\mathrm{mc} \text { ) }\end{array}$ & $\begin{array}{l}\text { Total, } \\
\text { male } \\
(n=1140)\end{array}$ & $\begin{array}{l}\text { Total, } \\
\text { female } \\
(n=1013)\end{array}$ & $\begin{array}{l}p \text {-value } \\
\text { (male vs. } \\
\text { female) }\end{array}$ \\
\hline Emotional Symptoms & $\begin{array}{l}3.41 \\
(1.88)\end{array}$ & $\begin{array}{l}4.18 \\
(2.06)\end{array}$ & $\begin{array}{l}2.92 \\
(1.92)\end{array}$ & $\begin{array}{l}3.18 \\
(2.06)\end{array}$ & $\begin{array}{l}3.82 \\
(2.01)\end{array}$ & $\begin{array}{l}3.03 \\
(1.98)\end{array}$ & $<0.001$ & $\begin{array}{l}3.07 \\
(1.92)\end{array}$ & $\begin{array}{l}3.58 \\
(2.11)\end{array}$ & $<0.001$ \\
\hline Conduct Problems & $\begin{array}{l}2.70 \\
(1.56)\end{array}$ & $\begin{array}{l}2.42 \\
(1.49)\end{array}$ & $\begin{array}{l}2.61 \\
(1.69)\end{array}$ & $\begin{array}{l}2.14 \\
(1.56)\end{array}$ & $\begin{array}{l}2.55 \\
(1.53)\end{array}$ & $\begin{array}{l}2.41 \\
(1.65)\end{array}$ & 0.048 & $\begin{array}{l}2.64 \\
(1.65)\end{array}$ & $\begin{array}{l}2.25 \\
(1.54)\end{array}$ & $<0.001$ \\
\hline Hyperactivity & $\begin{array}{l}4.44 \\
(2.02)\end{array}$ & $\begin{array}{l}4.08 \\
(2.11)\end{array}$ & $\begin{array}{l}4.01 \\
(2.15)\end{array}$ & $\begin{array}{l}3.55 \\
(2.17)\end{array}$ & $\begin{array}{l}4.25 \\
(2.08)\end{array}$ & $\begin{array}{l}3.81 \\
(2.17)\end{array}$ & $<0.001$ & $\begin{array}{l}4.15 \\
(2.12)\end{array}$ & $\begin{array}{l}3.76 \\
(2.16)\end{array}$ & $<0.001$ \\
\hline Peer Problems & $\begin{array}{l}2.79 \\
(1.65)\end{array}$ & $\begin{array}{l}2.85 \\
(1.66)\end{array}$ & $\begin{array}{l}2.95 \\
(1.64)\end{array}$ & $\begin{array}{l}2.63 \\
(1.52)\end{array}$ & $\begin{array}{l}2.82 \\
(1.66)\end{array}$ & $\begin{array}{l}2.81 \\
(1.60)\end{array}$ & 0.898 & $\begin{array}{l}2.90 \\
(1.64)\end{array}$ & $\begin{array}{l}2.72 \\
(1.58)\end{array}$ & 0.010 \\
\hline Total Difficulties Score & $\begin{array}{l}13.35 \\
(4.85)\end{array}$ & $\begin{array}{l}13.55 \\
(5.10)\end{array}$ & $\begin{array}{l}12.44 \\
(5.17)\end{array}$ & $\begin{array}{l}11.43 \\
(5.19)\end{array}$ & $\begin{array}{l}13.46 \\
(4.99)\end{array}$ & $\begin{array}{l}12.00 \\
(5.20)\end{array}$ & 0.020 & $\begin{array}{l}12.73 \\
(5.09)\end{array}$ & $\begin{array}{l}12.30 \\
(5.26)\end{array}$ & 0.059 \\
\hline Prosocial & $\begin{array}{l}6.26 \\
(1.99)\end{array}$ & $\begin{array}{l}7.05 \\
(1.85)\end{array}$ & $\begin{array}{l}6.57 \\
(2.08)\end{array}$ & $\begin{array}{l}7.33 \\
(1.94)\end{array}$ & $\begin{array}{l}6.68 \\
(1.95)\end{array}$ & $\begin{array}{l}6.90 \\
(2.05)\end{array}$ & $<0.001$ & $\begin{array}{l}6.47 \\
(2.05)\end{array}$ & $\begin{array}{l}7.22 \\
(1.91)\end{array}$ & $<0.001$ \\
\hline
\end{tabular}

Table 4 Behaviors problems by child group and gender, $\mathrm{n}(\%)$

\begin{tabular}{|c|c|c|c|c|c|c|c|c|c|c|c|}
\hline & & $\begin{array}{l}\text { LBC }, \\
\text { male } \\
(n=353)\end{array}$ & $\begin{array}{l}\text { LBC, } \\
\text { female } \\
(n=408)\end{array}$ & $\begin{array}{l}\text { MC, } \\
\text { male } \\
(n=787)\end{array}$ & $\begin{array}{l}\text { MC, } \\
\text { female } \\
(n=605)\end{array}$ & $\begin{array}{l}\text { Total, } \\
\text { LBC } \\
(n=761)\end{array}$ & $\begin{array}{l}\text { Total, } \\
\text { MC } \\
(n=1392)\end{array}$ & $\begin{array}{l}p \text {-value } \\
\text { (lbc vs. } \\
\mathrm{mc} \text { ) }\end{array}$ & $\begin{array}{l}\text { Total, } \\
\text { male } \\
(n=1140)\end{array}$ & $\begin{array}{l}\text { Total, } \\
\text { female } \\
(n=1013)\end{array}$ & $\begin{array}{l}p \text {-value } \\
\text { (male vs. } \\
\text { female) }\end{array}$ \\
\hline Smoking ${ }^{a}$ & & $\begin{array}{l}56 \\
(16.0)\end{array}$ & $\begin{array}{l}11 \\
(2.7)\end{array}$ & $\begin{array}{l}88 \\
(11.3)\end{array}$ & $\begin{array}{l}23 \\
(3.8)\end{array}$ & $\begin{array}{l}67 \\
(8.8)\end{array}$ & $\begin{array}{l}111 \\
(8.0)\end{array}$ & 0.572 & $\begin{array}{l}144 \\
(12.7)\end{array}$ & $\begin{array}{l}34 \\
(3.4)\end{array}$ & $<0.001$ \\
\hline Drinking ${ }^{\mathrm{b}}$ & & $\begin{array}{l}120 \\
(34.4)\end{array}$ & $\begin{array}{l}78 \\
(19.2)\end{array}$ & $\begin{array}{l}241 \\
(31.0)\end{array}$ & $\begin{array}{l}106 \\
(17.6)\end{array}$ & $\begin{array}{l}198 \\
(26.2)\end{array}$ & $\begin{array}{l}347 \\
(25.2)\end{array}$ & 0.627 & $\begin{array}{l}361 \\
(32.1)\end{array}$ & $\begin{array}{l}184 \\
(18.3)\end{array}$ & $<0.001$ \\
\hline $\begin{array}{l}\text { Cheating } \\
\text { exams }^{c}\end{array}$ & on & $\begin{array}{l}141 \\
(39.9)\end{array}$ & $\begin{array}{l}113 \\
(28.0)\end{array}$ & $\begin{array}{l}124 \\
(15.8)\end{array}$ & $\begin{array}{l}73 \\
(12.1)\end{array}$ & $\begin{array}{l}254 \\
(33.6)\end{array}$ & $\begin{array}{l}197 \\
(14.2)\end{array}$ & $<0.001$ & $\begin{array}{l}265 \\
(23.3)\end{array}$ & $\begin{array}{l}186 \\
(18.5)\end{array}$ & 0.007 \\
\hline Stealing $^{c}$ & & $29(8.2)$ & $18(4.4)$ & $53(6.8)$ & $16(2.7)$ & $47(6.2)$ & $69(5.0)$ & 0.279 & $82(7.2)$ & $34(3.4)$ & $<0.001$ \\
\hline $\begin{array}{l}\text { Bullied } \\
\text { others }^{c}\end{array}$ & by & $\begin{array}{l}204 \\
(58.1)\end{array}$ & $\begin{array}{l}200 \\
(49.1)\end{array}$ & $\begin{array}{l}399 \\
(50.9)\end{array}$ & $\begin{array}{l}202 \\
(33.6)\end{array}$ & $\begin{array}{l}404 \\
(53.3)\end{array}$ & $\begin{array}{l}601 \\
(43.4)\end{array}$ & $<0.001$ & $\begin{array}{l}603 \\
(53.1)\end{array}$ & $\begin{array}{l}402 \\
(39.9)\end{array}$ & $<0.001$ \\
\hline
\end{tabular}


Table 5 Selected indictors as categorical variables by migration status: percentages, crude and adjusted odds ratios

\begin{tabular}{|c|c|c|c|c|c|c|}
\hline & $\mathrm{LBC}$ & $M C^{g}$ & $\begin{array}{l}\text { Crude OR } \\
(95 \% \mathrm{Cl})\end{array}$ & $p$-value & $\begin{array}{l}\text { Adjusted OR } \\
(95 \% \mathrm{Cl})\end{array}$ & $p$-value \\
\hline \multicolumn{7}{|l|}{ SDQ subscale } \\
\hline Emotional Symptoms: abnormal ${ }^{a}$ & 10.4 & 6.2 & $1.76(1.28,2.42)$ & 0.001 & $1.65(1.19,2.28)$ & 0.003 \\
\hline Conduct Problems: abnormal ${ }^{b}$ & 11.5 & 11.3 & $1.01(0.77,1.34)$ & 0.923 & $1.06(0.80,1.41)$ & 0.692 \\
\hline Hyperactivity: abnormal' & 12.4 & 11.0 & $1.14(0.87,1.50)$ & 0.346 & $1.15(0.87,1.52)$ & 0.336 \\
\hline Peer Problems: abnormal ${ }^{d}$ & 6.0 & 5.0 & $1.22(0.83,1.80)$ & 0.312 & $1.40(0.94,2.09)$ & 0.095 \\
\hline Total Difficulties Score: abnormale & 11.4 & 8.8 & $1.33(0.99,1.78)$ & 0.061 & $1.36(1.01,1.84)$ & 0.042 \\
\hline Prosocial: abnormal ${ }^{f}$ & 89.7 & 91.5 & $0.81(0.60,1.09)$ & 0.162 & $0.71(0.52,0.97)$ & 0.032 \\
\hline \multicolumn{7}{|l|}{ Risk behaviors } \\
\hline $\begin{array}{l}\text { Smoking ever/more than } 1 \text { cigarette per } \\
\text { week }\end{array}$ & 8.8 & 8.0 & $1.11(0.81,1.53)$ & 0.517 & $1.24(0.89,1.71)$ & 0.204 \\
\hline $\begin{array}{l}\text { Drinking ever/more than } 1 \text { times per } \\
\text { month }\end{array}$ & 26.2 & 25.2 & $1.06(0.86,1.30)$ & 0.591 & $1.14(0.93,1.41)$ & 0.217 \\
\hline Cheating on exams sometimes/often & 33.6 & 14.2 & $3.05(2.46,3.77)$ & $<0.001$ & $3.07(2.47,3.83)$ & $<0.001$ \\
\hline Stealing sometimes/often & 6.2 & 5.0 & $1.26(0.86,1.84)$ & 0.238 & $1.50(1.02,2.22)$ & 0.042 \\
\hline Bullied by others sometimes/often & 53.3 & 43.4 & $1.49(1.25,1.78)$ & $<0.001$ & $1.76(1.46,2.13)$ & $<0.001$ \\
\hline
\end{tabular}

a: The cut-off level for abnormal is 7 and above; b: The cut-off level for abnormal is 5 and above; c: The cut-off level for abnormal is 7 and above; d: The cut-off level for abnormal is 6 and above; e: The cut-off level for abnormal is 20 and above; f: The cut-off level for abnormal is 0 to 4 ;

g: LBC:left-behind children; MC: migrant children;

h: Reference group is LBC. Adjusted by gender, grade and self-rated household income. 
